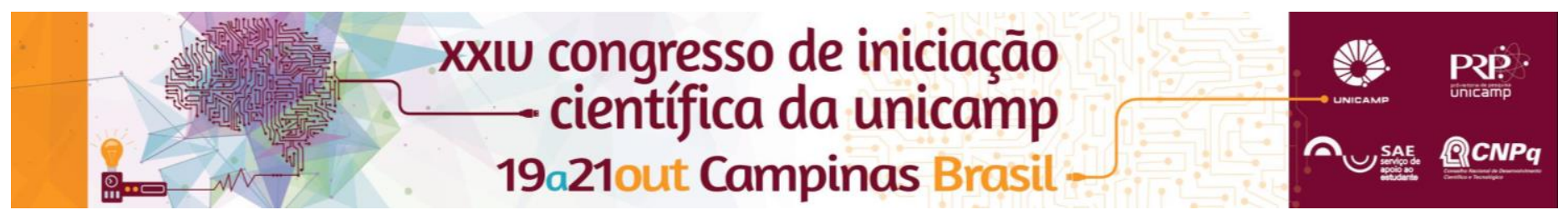

\title{
Otimização do Ensaio de Jar Test utilizando-se técnicas quimiométricas
}

\section{Priscila Morgon Arruda*, Enelton Fagnani}

\section{Resumo}

O teste de jarros (Jar Test) é essencial na caracterização de águas para fins de potabilização, onde são simuladas em reatores estáticos as condições operacionais para o tratamento convencional que ocorre na estação de tratamento de águas (ETA). São necessários em torno de 90 resultados para se construir o diagrama de coagulação com as curvas de isovalor. Os diagramas obtidos em laboratório permitem definir as regiões mais eficientes na remoção da turbidez para comparar o método com técnicas quimiométricas de planejamento experimental, com posterior construção da superfície de resposta. A finalidade é reduzir o número de ensaios e recursos e minimizar a quantidade de resíduos químicos gerados.

Palavras-chave: Diagrama de coagulação, tratamentos físico-químicos, otimização de metodologias analíticas.

\section{Introdução}

O tratamento de água tem por finalidade enquadrar a água no padrão de potabilidade para fins de abastecimento público. Para avaliar a eficácia do tratamento, o principal parâmetro utilizado é a turbidez ${ }^{1}$, ocasionada pela presença de argilas, lodos e microrganismos em suspensão. Através da adição de coagulantes essas partículas podem ser desestabilizadas de acordo com três mecanismos: compressão da dupla camada, adsorção-desestabilização e varredura.

Pela dificuldade de construção e instalação de um projeto piloto de uma ETA, pode-se utilizar um reator estático de bancada, o Jar Test. Assim é possível construir o diagrama de coagulação com base no par de valores dosagem do coagulante e $\mathrm{pH}$ de coagulação, por meio dos quais pode-se gerar curvas de isoeficiência de acordo com - parâmetro de controle que se pretende estudar, nesse caso a turbidez remanescente.

\section{Resultados e Discussão}

A água bruta utilizada é proveniente do manancial denominado Ribeirão Pinhal, no município de Limeira - SP. Nas Figuras 1 e 2 encontram-se os diagramas de coagulação em função da turbidez remanescente, obtidos com o policloreto de alumínio (PAC) como coagulante.

Figura 1. Diagrama de coagulação da coleta 1.

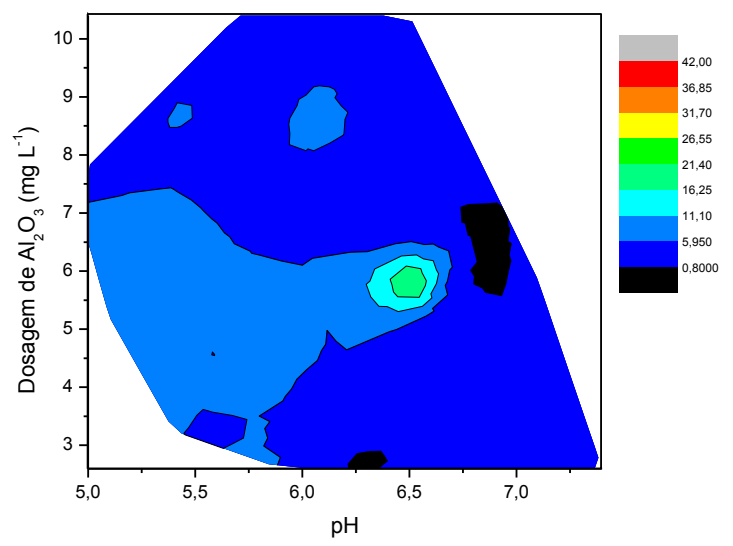

Figura 2. Diagrama de coagulação da coleta 2.

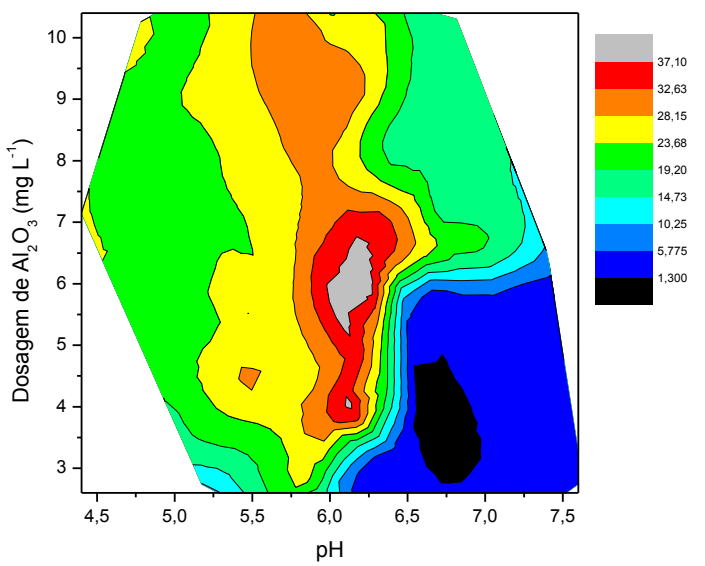

Tabela 1. Regiões com maior eficiência na remoção da turbidez.

\begin{tabular}{cccc}
\hline $\begin{array}{c}\text { Diagrama } \\
\text { de }\end{array}$ & pH & $\begin{array}{c}\text { Dosagem } \\
\text { de } \mathbf{A l}_{2} \mathbf{O}_{3} \\
\text { coagulação }\end{array}$ & $\begin{array}{c}\text { Turbidez } \\
\text { remanescente } \\
\text { (uT) }\end{array}$ \\
\hline 1 & $6,25-6,5$ & $<3,0$ & $<0,8$ \\
\hline 2 & $6,75-7,0$ & 5,5 a 7,0 & $<1,3$ \\
\hline
\end{tabular}

\section{Conclusões}

A região ótima para coagulação-floculação pelo método de varredura foi determinada pelos diagramas de coagulação. A próxima etapa consiste na escolha e na aplicação de ferramenta quimiométrica adequada, visando reduzir o número de experimentos.

\section{Agradecimentos}

À FAPESP (proc. 2015/14137-3) pela bolsa concedida e ao CNPq.

\footnotetext{
${ }^{1}$ LIBÂNIO, M. Fundamentos de qualidade e tratamento de água. $2^{\mathrm{a}}$ edição. Campinas: Átomo, 2008. 444 p.
} 